\title{
Study on the application of three dimensional knowledge system in the experimental course of clinical medicine specialty Histoembryology in Higher Vocational Education
}

\author{
Xudong Chen, Xiaolan Wang ${ }^{\mathrm{a}, *}$
}

Department of Histology and embryology, Luohe Medical College, Luohe, 462000, China

aemail: 573373763@qq.com

\begin{abstract}
Keywords: histoembryology; experimental course; three dimensional knowledge system
\end{abstract}
\begin{abstract}
To explore the learning effects of histoembryology experimental course of higher vocational college students, we constructed a application of three-dimensional knowledge system in experimental teaching of histoembryology. Results showed that experimental group using three-dimensional knowledge system in experimental course, experimental exam achievement and learning interest are higher than that of the ordinary group. This teaching method can directly reflects the students, ability of hands-on mental, practical physical ability, thinking independently,and mastery of basic theoretical knowledge.It is a good experiment teaching method with high reliability.
\end{abstract}

\section{Introduction}

Histoembryology is a verification science, mainly study on morphology and structure of micro. Abstract theoretical knowledge must be obtained by means of a microscope to gain visualization and perceptual knowledge, so as to strengthen students' understanding and mastery of the subject's knowledge. At the same time, through the specific experimental operation to cultivate students' ability of practice, analyze and solve problems, therefore, the teaching quality of the experimental course is particularly important in the teaching process.

In recent years, with the development of science and technology information, the traditional teaching mode, teaching methods and teaching means is difficult to meet the requirements of modern teaching. Therefore, we should pay attention to culture the students' ability of learning , innovative spirit and creative ability, so that students can learn independently. The traditional exam oriented education has been unable to meet the demand of talents in the new century, building a experimental course mode of histoembryology is the trend of the times[1]. Course three-dimensional system is conducive to the cultivation of students' learning ability, innovative ability and practical ability, but also with special emphasis on the theory of practical ability and self-learning ability[2].

\section{Object of study}

The objects of this study are three years clinical specialty(class1 and class 2), the number of students were 195 and 196 , classes one was randomly set as the experimental class, class two as the control class. There was no significant difference in the total score and sex ratio between the two classes $(\mathrm{P}>0.05)$. There are go all the way in courses teachers, teaching content, teaching schedule and the number of Class hours in two classes.

\section{Research method}

\section{Curriculum and examination arrangement}

Theory course schedule of the two classes are exactly same and arrange to have classes in the first semester. The theory exams are close books and notes, the maximum mark is 100 . However, the experimental course is arranged in the second semester, the physiological and pathological courses 
are going on at same time.Three-dimensional knowledge system was used in experimental class in experimental course, three-dimensional system of histoembryology course construction contained the breadth and depth of knowledge, the teaching way and method and knowledge representation. Through the combination of teaching and learning, highlighting the training of learning ability; through the combination of learning and practice, strengthen the training of practical ability; through the combination of before class, class and after class, strengthen the cultivation of innovative ability. 30 kinds of tissue sections as the experimental examination scope.The examination procedure is as follows: Teachers will chose the typical picture of tissue section in test scope into the examination question bank, 10 cards were randomly selected and played through the slideshow in every examination, Students are required to write the organization name and designated 1-2 kinds of characteristics of the structure. Each score 10 points, a total of 100 points.

\section{Control class}

Experimental teaching method which is widely used in the University was used in control class, namely the teacher explains the teaching, the students observe, plot, and hand in the homework.

\section{Experimental class}

Three-dimensional knowledge system was used for experimental teaching, specific as follows: 1 . Before class, teachers layout preview topic, students with questions from the breadth and depth of knowledge ,so that to do a good preparation before class. For example, the assignment of the blood section is as follows: (1) Why patients should be tested blood immediately after admission? what's in the blood?what is the doctor wants to know? (2) Why the blood is red, and why it will stop bleeding and other issues, so that students obtain a wider range of knowledge through access to information before class.2.In class, in the teaching process, we will be the conclusion of the teaching process into the process of teaching, will be a one-way infusion into a more interactive inquiry teaching, the students into the teaching of passive learning into the inherent thinking mode of teaching.Ways and methods can effectively guide students to use scientific research methods to sum up, reasoning and argumentation, draw the conclusion, and then create the existing knowledge, training students' innovation ability.3.After class, In addition to allow students to complete the homework drawing and layout some subjects that challenges and follow-up courses related, which can stimulate the curiosity of the tudents. For example,epithelial tissue

in the body surface of the body, or have a cavity organs inside surface, plays a protective role, but the epithelial lesions will happen under the long-term adverse stimulation, combined with pathology metaplasia, talk about ideas.

\section{Questionnaire survey}

After the end of the experiment, the questionnaire was used to investigate the students who participated in the study.

\section{Data processing}

Measurement data using $\mathrm{t}$ test. Statistical calculation are completed through the SPSS17.0 software.

\section{Result}

Results experimental and theoretical of two classes are shown in Table1

Table1 Experimental results and theoretical results of two classes( $\left.\bar{x}_{ \pm s}\right)$

\begin{tabular}{|c|c|c|c|}
\hline class & $\mathrm{n}$ & theoretical results & experimental results \\
\hline Experiment & 195 & $85.12 \pm 3.23^{\triangle}$ & $88.24 \pm 2.12^{*}$ \\
\hline Control & 196 & $84.48 \pm 2.26$ & $81.16 \pm 1.90$ \\
\hline
\end{tabular}

*VScontrol class, $\mathrm{p}<0.05 ; \quad \triangle$ VScontrol class,p $>0.05$

\section{Results of questionnaire}

In view of the students participating in the study, 391 questionnaires were issued and 389 
questionnaires were recovered,all questionnaires are valid. Results shown that using three-dimensional knowledge system in experimental course was received by majority of the students, so that we have the interest to the classroom and improves the learning efficiency, more conducive to persist in learning, the teaching method has also been recognized by the majority of students, recommended promotion.

\section{Discussion}

Histoembryology is an important basic course of medicine, belong to morphology discipline,is an in-depth study of anatomy and the basis of the physiology and pathology of learning.Content of courses includes theoretical teaching and experimental teaching.Experimental teaching is not only important means of the cultivation ability of students' practical, analyse problem and solve problem, but also is effective measures for further deepen the understanding of theoretical knowledge and strengthen to memorize knowledge.

In order to cross learning between various disciplines, to further promote the cohesion of histoembryology with physiology and pathology. 3 year clinical professional curriculum reform was carried out in our school.Histoembryology experiment arrangement in the second semester. Therefore, it is the best time for building three-dimensional knowledge system in experimental course ,lets the students to increase the breadth and depth of knowledge and to promote the relationship between disciplines.

From table 1 data analysis can be seen, two classes of the same theory teaching has no effect on theory achievement, the theoretical results of two classes without statistical significance. Experimental results of the experimental class was significantly higher than that in the control group, and the difference has statistical significance, indicating that the constructed three-dimensional knowledge system in experimental teaching of histoembryology application can significantly improve the performance. Above results showed that the construction of application of three-dimensional knowledge system in experimental teaching of histoembryology, and truly reflect the students' practical ability and the basic theory of knowledge to grasp the situation, promote their interest in study, improve the learning effect.

In recent years, with the advent of the era of information, histoembryology experiment teaching hardware facilities happened great changes, from traditional payment section, students using a microscope to observe, to high-tech new product use, such as morphological and microscopic digital interactive system virtual experiment equipment application[4-6].But few people pay attention to the use of interdisciplinary new teaching methods, traditional teaching methods was commonly used in class, teachers' simple teaching in class, students observe the sections or virtual slice, this approach is not conducive to the expansion of students' knowledge, even some students feel boring and perfunctory classroom and homework, the teaching effect is not ideal. But three-dimensional knowledge system in the use of the experimental teaching concept is the student must be involved in solving practical problems ${ }^{[3]}$, and activate the existing knowledge and it as the basis for new knowledge, showed the new knowledge to the students and students to apply new knowledge.New knowledge and the life world of students into one.It is emphasized that effective teaching based on two principles: the teaching content of reasonable and useful teaching activities

Through this study, we found that there are many advantages, the specific performance is flow (1)Contribute to the cultivation of learning ability, the teaching process is a take the student as the main body, the teacher is the dominating the process, is the "teaching" and "learning" two-way process, not only pay attention to the teacher one-way to impart knowledge, but should take the student as the center, the students main body status in teaching activities; the leading role of teachers reflected in guidance and counseling students learning.Teachers imparting of knowledge should be given priority to with inspiration, guidance, focus on training the students' self learning ability, make students actively participate in the teaching process, has the strong ability of autonomous learning. Build interactive classroom, motivation of students' autonomous learning, multi-channel access to knowledge. (2) Strengthen the cultivation of three-dimensional learning 
ability,the basic purpose of learning is to apply and to solve practical problems. Encourage students to combining the reality of disciplines, multidisciplinary knowledge to understand cross study fundamentally to solve the problem. Strengthening the combination of between disciplines in class, guide the students found the problem, in-depth discussion and analysis of practical problems and training students' ability to analyze and solve problems of practice. (3) Strengthening the cultivation of innovation ability, it is mainly reflected in the combination of class and after class, in the class, teachers must pay attention to heuristic method of teaching, encourage students to boldly challenged, the courage to innovate. Outside the classroom, teachers should pay attention to the practice of the cultivation of students innovative ability, encouraging students to take an active part in all kinds of college students' extracurricular activities such as scientific and technological innovation, make it get better exercise in these activities, thought to society to lay a solid foundation in the future. So,the construction of three-dimensional system has formed open teaching that the student as the main body, teacher as the leading factor of active,the teaching process into a two-way activity of teaching and learning process, fully mobilize the initiative of student learning, exercise the students' learning ability, practical ability and create new ability is worth further popularization and application.

\section{Acknowledgement}

In this paper, the research was sponsored by the education technology and equipment and practice education research project topics in Henan Province In 2015 (Project No. GZS113).

\section{References}

[1] Jinhua Wang, Jianhai Chen,Qichuan Huang,et al. Construction and application of the three-dimensional experiments textbooks of histology and embryology for the university undergraduates. Chinese Journal of Anatomy[J].2016,39(1):131-132.

[2] Hongying Zhang,Yuan Zou,Jianing Zhang,et al. Build training innovative practice ability of medical morphological three-dimensional teaching system.Chinese higher medical education [J].2012,11:81-83

[3] Yuying Zhang,Siqi Wu,Qin Jia,et al. Build a new type of histology and embryology experiment teaching mode.Progress of Anatomical Sciences [J].2012,18(4):388-389

[4] Yonghong Lan, Haiyan Niu, Qun Li, et al. The virtual microscope system in the application of morphology experimental teaching. Chinese higher medical education [J].2011,4

[5] Linzhi Guo,Aixiu Qiao,Xiaohun Wang. Motic digital microscope interactive system in the role of pathological experiment teaching reform .Basic Medical Education [J].2015,17(1):75-77

[6] Guorong Zhang, Fanjie Meng, Wenqi Wang. Digital section in teaching the application of histoembryology . Medical education and technology of China [J].2015,17(1):75-77 